\title{
Case/Real-Life Problem-Based Experiential Learning with Information System Projects
}

\author{
Zbigniew J. Gackowski \\ California State University Stanislaus, Turlock, California
}

\section{zgacko@koko.csustan.edu}

\begin{abstract}
The focus of this paper is case and real-life problem-based (Ewell, 1997) experiential learning with computer information system projects at California State University Stanislaus. The experiential learning occurs within a four-stage cycle: concrete experience, reflective observation, abstract conceptualization, and active experimentation. The four principles and strategies applied to bring knowing and doing together are: concreteness, involvement, dissonance, and reflection. The paper shows how the four types of learning environments (affective, perceptually oriented, symbolic, behavioral) are implemented, and student teams guided. Multi-disciplinary aspects of experiential education, and drawbacks specific to the academic environment in assessing students' performance in team projects are discussed.
\end{abstract}

Keywords: Information systems, problem-based learning, practice.

\section{Introduction}

While teaching courses on computer information system, in particular Systems Analysis and Design, it is easy to spot students' difficulties in incorporating what they have learned in one course into a different course. Students, when subjected to testing how they mastered the required prerequisites, are surprised to realize that:

- Introduction to management information systems has already covered much, if not most of the basic terminology and concepts needed in any subsequent courses on information systems.

- Economics, accounting, production operations management, quantitative methods, marketing, and finances have provided them with the necessary business background with regard to how organizations do and should operate. Such a background is indispensable for developing viable business or administrative information systems. Relevant technological issues can be addressed later.

- Statistics, the basic tool in management science and theory of information, is also indispensable for any meaningful quantitative analysis of business or administrative entities.

Perhaps all too often we instructors present to students the pertinent subject-matter material for memorization only rather than for deep absorption within the con-

Material published as part of these proceedings, either on-line or in print, is copyrighted by Informing Science. Permission to make digital or paper copy of part or all of these works for personal or classroom use is granted without fee provided that the copies are not made or distributed for profit or commercial advantage AND that copies 1) bear this notice in full and 2) give the full citation on the first page. It is permissible to abstract these works so long as credit is given. To copy in all other cases or to republish or to post on a server or to redistribute to lists requires specific permission from the publisher at Publisher@InformingScience.org text of a real-life experience. Then, how can we help students translate what they know from CIS and other courses into effective system design and implementation? Experiential learning is one of the proven approaches to overcome the large gap between knowing and doing. Hence, case and real-life problem-based group projects assigned to student teams 
provide the proper context and stimulus for learning with superior retention rate. An increased attention to problem-based learning, and active learning in general, is certainly warranted.

Based on published research, Ewell (1997) emphasizes among others that: direct experience shapes ind ividual understanding. Learning occurs best in the context of engaging with a compelling problem, and with substantial interaction among students, with the instructor, and even better with outside sources.

At California State University Stanislaus the CIS undergraduate program offers students a sequel of CIS courses in System Analysis and Design, Information Systems Design and a capstone course Application Development Project. In the first two courses case problem-based projects are assigned to student groups. In the capstone course students are encouraged to select their own real-life problem-based information system development project in business or administration. The instructor assigns projects only to those students who seem to be unable to find on their own a project that meets real-life user requirements and the specified minimum academic requirements. A team of students does every project, since as a rule CIS majors will conduct their professional activities in teams. Their professional education must encompass interpersonal work relations and group dynamics with broad communication skills in gathering information, presenting project proposals, and documenting what they have accomplished in the form of system documentation that simultaneously constitutes a show-case type student le arning portfolio within the academic environment.

\section{Stages in Experiential Learning and in Information Systems Projects}

Kolb (1984) defined four stages in experiential learning. As shown in Figure 1, the immediate concrete experience $(\boldsymbol{C E})$ is initiated by assigning a selected case or a real-life problem together with a list of tasks to be performed. Direct experience decisively shapes individuals' understanding, and a compelling problem stimulates the learners' faculties.

Beyond stimulation, learning requires reflective observation (RO). It takes place during investigation of bus iness or administrative systems by studying, reading, observing, questioning, and intervie wing.

The gathered information is analyzed, assimilated and transformed into a concept of an improved computer information system. General (logical, preliminary, functional or initial) design of systems alternatives based upon

Figure 1. The Experiential Learning Model

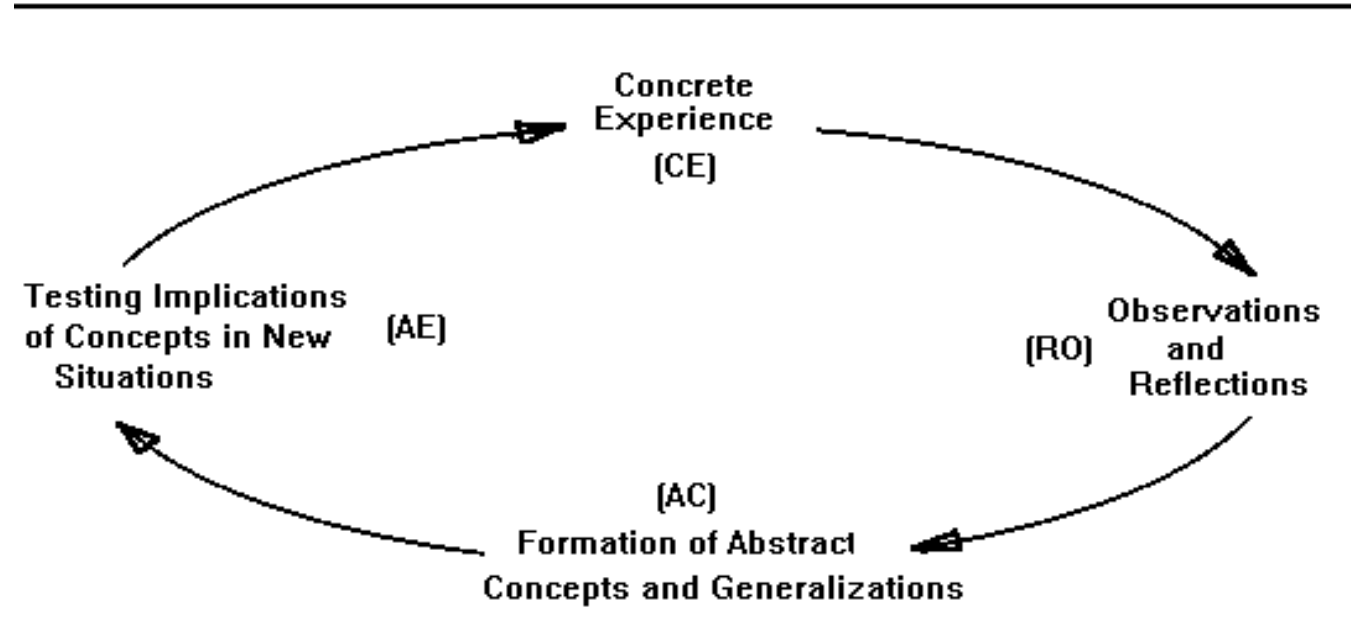

Source: Kolb, 1984 
the prior reflective observation constitutes an abstract conceptualization $(A C)$ of the system. Subsequently, the new concept has to undergo a thorough feasibility study and be presented as a project proposal to end-users and their management. The purpose of this stage is to obtain the go-ahead decision for the new system.

The approved project proposal provides guid ance for further actions. The development, testing, and implementation of the designed information sys tem constitute an example of active experimentation $(\boldsymbol{A E})$ by student teams. Thus students are immersed into all aspects of experiential learning, as defined by Kolb (1984). A side-by-side comparison of Kolb's stages of experiential learning and the stages and steps in developing information system projects is given in Table 1.

In real life, later, regular operations of the system create a new concrete experience (CE) with subsequent opportunities for new reflective observation (RO), etc. In an academic environment, we are limited only to the system development cycle. Within a single semester we are unable to cover the entire system life cycle. Regular operations and pertinent sys tem maintenance activities continue until the final decision to discontinue the system or to replace it by a subsequent version is implemented.

\section{Principles and Strategies of Experiential Learning}

Hutchings and Wutzdorff (1988) identified four principles and strategies to bring knowing and doing together: concreteness, involvement, dissonance, and reflection. Problem-based information system development

\section{Stages in Experiential Learning and IS Projects}

\begin{tabular}{ll|l}
\hline $\begin{array}{c}\text { Stages in } \\
\text { Experiential Learning }\end{array}$ & \multicolumn{1}{c}{$\begin{array}{c}\text { Stages in } \\
\text { IS Senior Projects }\end{array}$} \\
\hline 1- Concrete experience & (CE) & IS Case + Task \\
2- Reflective Observation & (RO) & $\begin{array}{l}\text { Investigation } \\
\text { Analysis }\end{array}$ \\
3- Abstract Conceptualization (AC) & $\begin{array}{l}\text { General Design } \\
\text { Feasibility Study } \\
\text { Project Proposal }\end{array}$ \\
4- Active Experimentation & (AE) & $\begin{array}{l}\text { Physical Design } \\
\text { Implementation }\end{array}$ \\
\hline
\end{tabular}

Table 1: Stages in Experiential Learning and IS Projects 


\section{Case/Real-Life Problem-Based Experiential Learning}

projects provide close to real-life experiences into the students' learning process.

Concreteness is brought into the learning process not only by the assigned case, real-life problem and the assigned tasks but also by the very fact that students have to organize the entire process. During the first session students learn the nature of cases available to students or potentially acceptable real-life projects for selection. While taking the capstone course students are also fully aware that they work not only for a letter grade but also for the satisfaction of a real-life external user. Some of those users may have pretty high expectations. Even more, they may be students' prospective bosses, employers, or clients who watch with real interest their performance and attitude towards the assigned project. Next, students are told to form groups and begin to work in teams. At first, students have to apply what they have learned from prerequisite courses. Ewell (1997) emphasizes: "Learning occurs best in a cultural context that provides both enjoyable interaction and substantial personal support".

Within the context of the subject domain pertinent to the assigned application, in the frustration and confusion that inevitably follow, students directly face several challenges, such as:

- Group dynamics (how groups select leaders, arrive at consensus, establish standards, and handle conflicts),

a Management of complex projects (what is a system development life cycle, a project request, a project plan and a budget),

- Operation of organizations and their information systems (handling transactions, processing information, and using it for decision making).

Most of those issues should have been covered by prerequisite courses, taken from different instructors, sometimes at different colleges, and frequently over a prolonged time span. Concreteness of the situation combined with challenging tasks generates involvement.

Involvement inevitably develops in such a setting. Many problems develop with regard to: assuming or assigning leadership of the group, assigning tasks, brainstorming team members to generate ideas, criticizing in a destructive or constructive manner, verifying ideas, resolving differences of opinions, recognizing the necessity of building consensus, meeting deadlines, making up for colleagues' deficiencies, evaluating self and peers, confronting different levels of motivation, attitudes, cultural differences, etc. Where deep involvement exists, there is plenty of opportunity for dissonance.

Dissonance, whether caused by external factors or generated internally, throws learners temporarily out of balance. Flaring emotions (dissonance) may be caused, for instance, by incomplete description of the case and/or incomplete project definition, conflicting goals and user requirements, need for tradeoffs, personality clashes within the team, inadequate motivation, and contributions by some team members, conflicts of members' values and attitudes, constraining deadlines and lack of resources. Here, real-life offers plenty of opportunities to counter Ewell's (1997 p. 54) expression "enjoyable interaction". Alas, it is frequently a painful disappointment leading many team members to wish they had done everything on their own. This experience is, however, as important as other components of experiential learning.

The above paragraph lists only a few examples of challenging dissonances. Dissonances, however, when followed by proper reflection, can constructively move students towards deeper understanding of principles and techniques used to cope with adverse situations. For instance, many conflicts and misinterpretations could be eliminated by: 
- Having an explicit description of the underlying business objectives, critical success factors, requirements and constraints imposed upon the project and approved in advance by management and endusers;

- Adequate planning of project tasks and as signing them to individual team members;

- Insisting from the very beginning upon students' accountability for the results;

- Agreeing in advance about statements of objectives, project standards, and generally accepted design principles, and

- By properly documenting one's work done, so that others can build upon it.

Thus, many internal conflicts among team members could be resolved sooner and without alienation of any team members. Failure frequently sows the seed of success, for dissonance prepares the ground for reflection.

Reflection naturally follows an experienced dissonance or failure. It is the key to turning both into a learning experience of a very lasting effect. It does not, however, come naturally to students to step back and ponder their experience, to derive from it some meaning or knowledge relevant to other experiences before making the next attempt. Motivation and opportunities for reflection have to be built into the process. As Ewell (1997) puts it in his paper titled "Organizing for Learning" reflection is one of the core components of a good learning environment. Situations that encourage reflection require some degree of distance and time. In my practice it is instilled by means of requiring the preparation of drafts for the consecutive assignments, usually within one week after their distribution. In class, the instructor discusses those drafts anonymously. Other means applied are: writing a weekly log of activities, periodical student peer evaluations, in structor or end-user reviews, presentation of the project proposal, first to the entire class and the instructor, next to the management and endusers of the project.

Yes, effective learning situations need to encompass sufficient time for reflection and thinking, and frequent feedback on performance. There is, however, a problem how the time is measured. The administrative approach at universities and colleges is to count the scheduled contact hours such as lectures, labs, and activities, in addition the time spent on homework or other than in-class hours. This does not suffice. According to our experience, the results may differ dramatically whether the same number of contact hours is spread over one, two or three class sessions per week and whether the entire course is spread over four, six or fifteen weeks. In most cases, administrators consider those alternatives as equivalent and a non-issue. Certainly, this aspect of learning requires more quantitative research and assessment of results. My observation provides strong anecdotal evidence that students need a much longer overall time span to fully internalize, absorb all the concepts, links and experiences. This way a lasting mental framework is created for their professional mode of thinking.

Another proven instruments to stimulate students' reflection are show case type student learning portfolios employed in most of professional CIS courses taught by me. Our students are required and encouraged to assemble a professionally prepared set of system documentation. One can identify at least the following motivating factors:

- System documentation is required to sell any system product.

- Impressive system documentation gets the attention of job interviewers, thus enhances students' employability.

- The same documentation can be later used as an example and point of reference in developing other projects. 
a Preparation of system documentation literally forces students to reflect thoroughly upon their entire semester-long work, and teaches how to present it to client's management and end-users in a structured and esthetically appealing manner.

Students taking the prerequisite courses in computer programming and systems analysis and design with me (Gackowski, 1991) are familiar with this practice, for they were required to prepare a preliminary draft for each weekly assignment. To motivate them, students earn about $25 \%$ of total credit points for submitting a draft for each weekly assignment. Drafts, however, are not graded. To not embarrass concerned students or to not inhibit their fellow students from airing critical comments, the most representative drafts are critically discussed in class without revealing who prepared them. Hence other students who care to take notes can substantially improve their final submissions. The other important purpose of requiring drafts is to stress that information system development is always an iterative process. Thus students experience the basic truth that no mature design was ever conceived at the first attempt. In addition, when instructors permit some resubmissions of assignments, students have even more opportunities for reflection, correction of errors and recovering from partial failures. During a 15-week semester there are seven to ten graded assignments, not counting the final recapitulative documentation, the oral presentation and the final demonstration of the deve loped system.

\section{Experiential Learning Environments}

According to Kolb and Lewis (1986), an effective learner needs to develop skills in handling and dealing with concrete experience, reflective observation, abstract conceptualization, and active experimentation. Those skills tend to gradually develop in learning environments that are simultaneously: affective, perceptually oriented, symbolic, and behavioral.

An affective environment emphasizes experiencing of concrete events (CE) when a case or real-life problem is presented and a task is assigned (see Fig. 1). Gathering information by using or contacting reat life sources and end-users with a subsequent analysis of the information constitutes reflective observation (RO). Designing alternative solutions followed by respective feasibility studies is an abstract conceptualization (AC) of the solution that later will be challenged during peer, end-user, and instruc tor reviews. The same pertains to system development and implementation that constitutes active experimentation (AE). Finally, testing and operations of the new computer information system again provides students with new concrete experience (CE).

A perceptually oriented environment emphasizes information gathering by learning how to ask the right questions, observe, prepare consistent, orderly, neat and esthetic proposals, present them in an effective professional manner, and finally, compile and assemble the recapitulative system documentation into a show-case type of student learning portfolio.

A symbolic environment emphasizes abstract conceptualizations represented by a formal project request, context diagrams, data flow diagrams, system flowcharts, structure charts, entity-relationship diagrams, state transition diagrams, class diagrams, interaction diagrams such as sequence and collaboration diagrams in Unified Modeling Language (UML), Gantt charts, etc.

A behavioral environment stresses action taking, having the learner apply the acquired knowledge and skills to solve real-life problems as a professional would do by planning, assigning tasks, scheduling them, organizing the team, motivating the less active members, writing, interviewing, preparing presentations to sell the project, and eventually organizing the final acceptance test to obtain sign-off of the project. In the capstone course the last item becomes the academic equivalent of the required final examination. 


\section{Drawbacks of Group Projects in Academic Environments}

Nevertheless, there are several drawbacks with in formation system group projects within an academic environment, for instance:

- A student group does not provide an opportunity for a controlled selection of individuals possessing proper professional skills and knowledge to combine them for their synergy. If it happens, it does by chance.

- Accountability for individual contributions can be thwarted by wrongly understood camaraderie or "false friendship" with the consequence of undermining the learning process for academically weaker individuals.

- Students must be instructed how to implement a division of labor that does not compromise academic objectives, and how to react effectively from the very beginning to in evitable differences in quality and speed of individual contributions, before these differences endanger the entire project and the cohesion, morale, and performance of the team as a whole.

In exceptional situations, to accommodate and compensate for those drawbacks, when a team is unable to tolerate an obstinate or non-performing team member, I offer the option of expulsion from a team with subsequent separate grading of the expelled member's work. In most cases it constitutes a sufficiently strong psychological threat to discourage such individuals from expecting that they will be "carried" by the rest of the team.

Thus while agreeing in general with the benefits of interpersonal collaboration, instructors should assure as much as possible that there exist a built-in accountability of individual team members for their fair participation in and contribution to the project. "Linking established concepts to new situations" to work as advertised "students must do the work themselves, and faculty must assiduously avoid "telling' them how to make those links" (Ewell, 1997, p. 54).

Here, however, we face another problem. Most peer and administrative reviews put too much emphasis on immediate results of students' evaluation of faculty teaching performance. Particularly for young tenure-track or part-time instructors there is plenty of temptation to show, tell, and help students too much in return for immediate favorable teaching evaluations. Tenured faculty or faculty with a substantial well established publication record can to some extent ignore that temptation in return for long-term favorable teaching evaluation coming in the form of cordial "thank-you" letters from graduates with a few years of professional experience in real professional situations. These more mature, hence more valid evaluations are sometimes a complete reversal what the same students wrote in their teaching evaluations made at the end of the course. They freely and frankly admit it. Those really concerned with the quality of education we offer to our students must become aware of this factor.

Faculty, however, frequently "question" the viability of case and in particular real-life problem based projects for several reasons:

口 Projects are very faculty-time intensive,

口 Faculty resources are always in short supply, and

a Fear due to lack of practical industrial experience, as it is the case with many university instructors. 


\section{Conclusion}

The realism of experiential learning brings into the process an element of excitement, active participation, and involvement. It inspires greater motivation, and finally provides very observable satisfaction derived from a demonstrable, tangible outcome. All tasks within an application development project are clearly interdependent, each contributing toward a common goal. All this does not only engages students' cognitive faculties but also touches affective, attitudinal, ethical and behavioral dimensions of learning. Psychological research has clearly confirmed that learning acquired through several modalities is more likely to "stick" with students. The above aspect immensely broadens students' overall perspective of the project, of the subject-matter domain, and subsequently of their entire professional future.

To graduate, students must not only complete the course requirements, but also must demonstrate, at specified levels of sophistication, ability for effective communications, analysis, problem solving, decision-making, social interaction, and regard for esthetic aspects of their presentations and system documentation. I witnessed previously seemingly mediocre students, when judged by their prior course work, literally growing during the seme ster long, sometimes longer, case or real-life problem based experiential learning. Sometimes, I could hardly recognize those dressed up individuals unexpectedly presenting their project to a real audience of endusers and managers in a nearly professional manner. They simply surpassed themselves when challenged by the real life experience.

Some of the students for the very first time admitted that embarking upon a real or close to real-life information system project provided them with comprehension of the roles of different courses they had to take. Sometimes; several years later; I receive moving thank-you letters as a follow-up praising the breakthrough experience of problem-based experiential learning.

The positive experience with projects in information systems resulted in a senior Application Develo pment Project available as a capstone course in our CIS Program at the College of Business Administration. Students in this program are granted a separate degree - BS in Computer Information Systems. From the perspective of my life-long experience in teaching information systems, we should never ask whether we can afford to require students to do case or real-life problem based information system projects. The advantages and benefits are vivid, clear, and overwhelming. In my opinion, the only legitimate question is how to provide students an opportunity of case and real-life problem-based experiential learning within the available resources. Such an experience will impress an enduring effect on their entire professional life. In the worst case scenario, when resources are critically limited a credit/no credit assessment could be substituted for a letter grade. At this stage of their education students frequently savior more a public expression of satisfaction from the end-user than the letter grade for their project.

\section{References}

Ewell, P. (December 1997). Organizing for learning - A new imperative. American Association for Higher Education Bulletin, pp. 52-55, Washington, DC.

Gackowski, Z. (May 1991). Teaching systems analysis and design with computers. Published in End-user computing: Productivity in the nineties edited by C. E. Tapie Rohm, Jr., and James D. Brodzinski. Proceedings of the International Information Management Conference 1991 (pp. 1-6), San Bernardino, CA, California State University San Bernardino.

Hutchings, P. \& Wutzdorff, A. (Fall, 1988). Experiential learning across the curriculum: Assumptions and principles. Published in Knowing and Doing: Learning through experience (pp. 5-20) edited by Pat Hutchings and Allen Wutzdorff. New Directions for Teaching and Learning, Number 35. San Francisco, CA: Jossey-Bass, Inc., Publishers.

Kolb, D. (1984). Experiential learning. Englewood Cliffs, NJ: Prentice-Hall. 


\section{Gackowski}

Kolb, D. \& Lewis, L. (June 1986). Facilitating experiential learning: Observations and reflections. Published in Experiential and simulation techniques for teaching adults (pp. 99-108) edited by Linda H. Lewis. New Directions for Continuing Education, Number 30. San Francisco, CA: Jossey-Bass, Inc., Publishers. 